\section{AB015. Skin disease activity and autoantibody phenotype are major determinants of blood interferon signatures in dermatomyositis}

\author{
Mika Tabata ${ }^{1}$, Kavita Sarin ${ }^{1}$, Nareh Marukian ${ }^{1}$, \\ Karen Page ${ }^{2}$, Christine Huard ${ }^{2}$, Shanrong Zhao ${ }^{2}$, \\ Donald Bennett ${ }^{2}$, Jillian Johnson ${ }^{2}$, \\ Kristen Johnson ${ }^{2}$, David Fiorentino ${ }^{1}$ \\ ${ }^{1}$ Department of Dermatology, Stanford University Medical Center, \\ Redwood City, CA, USA; ${ }^{2}$ Pfizer Worldwide Research, Development \\ \&amp; Medicine, Cambridge, MA, USA \\ Correspondence to: David Fiorentino. 450 Broadway, Pavilion C \#C-234, \\ Redwood City, CA, USA. Email: fiorski@stanford.edu.
}

Abstract: Interferon signaling is upregulated in dermatomyositis and thought to play a role in pathogenesis. An interferon gene signature in peripheral blood of dermatomyositis patients correlates with skin disease. However, studies have not analyzed how interferon signaling differs across dermatomyositis subtypes or with multiple organ system involvement. We hypothesized that strength and clinical utility of the dermatomyositis blood interferon signature depends on autoantibody subtype and clinical factors. Utilizing RNA sequencing of 377 blood samples derived from a cohort of 205 clinically phenotyped dermatomyositis patients, we found that blood interferon score is significantly elevated in the anti-MDA5 subtype compared to other subtypes (average 16.12, $\mathrm{P}<0.001$ ). Change in cutaneous disease area and severity indexactivity correlates most strongly with change in interferon score in anti-MDA5 $(\mathrm{R}=0.85, \mathrm{P}<0.001)$ patients, followed by anti-Tif- $1 \mathrm{~g}(\mathrm{R}=0.59, \mathrm{P}<0.001)$ and anti-SAE1 $(\mathrm{R}=0.64$, $\mathrm{P}=0.048)$. The correlation is weak in anti-Mi2 and antiNXP2 subtypes. These patterns persist after adjustment for lung disease, muscle disease, cancer, and medications. The correlation is stronger when baseline interferon score is greater than $1.5(\mathrm{R}=0.59, \mathrm{P}<0.001)$. The correlation is weaker in patients with active muscle disease and stronger in patients with active lung disease but is unaffected by cancer status. Using a large prospective dataset of DM patients, we demonstrate that interferon-driven gene expression as an activity measure in dermatomyositis is related to specific autoantibody subtypes and is impacted by clinical factors. Careful attention to antibody status and clinical factors could help inform interpretation of interferon biomarker data in future clinical trials.

Keywords: Dermatomyositis; type 1 interferon; autoantibody subtypes; anti-MDA5, biomarker

doi: 10.21037/atm.2021.AB015

Open Access Statement: This is an Open Access article distributed in accordance with the Creative Commons Attribution-NonCommercial-NoDerivs 4.0 International License (CC BY-NC-ND 4.0), which permits the noncommercial replication and distribution of the article with the strict proviso that no changes or edits are made and the original work is properly cited (including links to both the formal publication through the relevant DOI and the license). See: https://creativecommons.org/licenses/by-nc-nd/4.0/.

Cite this abstract as: Tabata M, Sarin K, Marukian N, Page K, Huard C, Zhao S, Bennett D, Johnson J, Johnson K, Fiorentino D. Skin disease activity and autoantibody phenotype are major determinants of blood interferon signatures in dermatomyositis. Ann Transl Med 2021;9(5):AB015. doi: 10.21037/atm.2021. $\mathrm{AB} 015$ 